\title{
CIRCUITOS E USOS DE MODELOS PEDAGÓGICOS RENOVADORES NO ENSINO SECUNDÁRIO BRASILEIRO NA DÉCADA DE 19501
}

DOI: http://dx.doi.org/10.1590/2236-3459/80587

\author{
Norberto Dallabrida' \\ 'Universidade do Estado de Santa Catarina (Udesc), Florianópolis/SC, Brasil
}

$\cos 80$

\section{Resumo}

Este trabalho se propõe a compreender a circulação e a apropriação de dois modelos pedagógicos franceses que resultaram na construção das classes secundárias experimentais no Brasil na década de 1950. Por um lado, coloca o foco sobre os usos feitos por algumas classes do sistema público paulista das classes nouvelles - ensaio educacional realizado no ensino secundário francês. De outra parte, procura compreender as experiências no ensino secundário em colégios católicos realizadas a partir da pedagogia personalizada e comunitária. Para tanto, esta análise histórica movimenta os conceitos de circulação e de apropriação de Roger Chartier e usa como fontes históricas especialmente relatórios oficiais e relatos de professores.

Palavras-chave: classes secundárias experimentais, classes nouvelles, pedagogia personalizada e comunitária.

\section{CIRCUITOS Y USOS DE MODELOS PEDAGÓGICOS RENOVADORES EN LA ENSEÑANZA SECUNDARIA BRASILEÑO EN LA DÉCADA DE 1950}

\begin{abstract}
Resumen
Este trabajo se propone a comprender la circulación y la apropiación de dos modelos pedagógicos franceses que resultaron en la construcción de las clases secundarias experimentales en Brasil en la década de 1950. Por un lado, pone el foco sobre los usos hechos por algunas clases del sistema público paulista de las classes nouvelles - ensayo educativo realizado en la enseñanza secundaria francesa. Por otra parte, procura comprender las experiencias en la enseñanza secundaria en colegios católicos realizados a partir de la pedagogía personalizada y comunitaria. Para ello, este análisis histórico mueve los conceptos de circulación y de apropiación de Roger Chartier y utiliza como fuentes históricas especialmente informes oficiales y relatos de profesores.

Palabras clave: clases secundarias experimentales, classes nouvelles, pedagogía personalizada y comunitaria.
\end{abstract}

\footnotetext{
1 O presente artigo é uma versão ampliada e reformatada do texto "Modelos pedagógicos franceses e renovação do ensino secundário brasileiro", apresentado no XII Congreso iberoamericano de Historia de la Educación Latinoamericana - Cihela, que se realizou em Medellín (Colombia) de 15 a 18 de março de 2016.
} 


\title{
CIRCUITS AND USES OF RENEWABLE PEDAGOGICAL MODELS IN THE BRAZILIAN SECONDARY EDUCATION IN THE 1950S
}

\begin{abstract}
This paper aims to understand the circulation and appropriation of two French pedagogical models that resulted in the construction of experimental secondary classes in Brazil in the 1950s. On the one hand, it focuses on the uses made by some classes of the public system of the nouvelles classes - an educational test carried out in French secondary education. On the other hand, it seeks to understand the experiences in secondary education in Catholic colleges based on personalized and community pedagogy. For this, this historical analysis moves the concepts of circulation and appropriation of Roger Chartier and uses as historical sources especially official reports and reports of teachers.

Keywords: experimental secondary classes, nouvelles classes, personalized and community pedagogy.
\end{abstract}

\section{CIRCUITS ET UTILISATIONS DE MODĖLES PÉDAGOGIQUES RENOUVELABLES DANS L'ENSEIGNEMENT SECONDAIRE BRÉSILIEN DANS LES ANNÉES 1950}

\section{Résumé}

Cet article vise à comprendre la circulation et l'appropriation de deux modèles pédagogiques français qui ont abouti à la construction de classes expérimentales au Brésil dans les années 1950. D'une part, il se concentre sur les usages de certaines classes du système public des classes nouvelles - un test éducatif effectué dans l'enseignement secondaire français. D'autre part, il cherche à comprendre les expériences de l'enseignement secondaire dans les collèges catholiques basées sur en la pédagogie personnalisée et communautaire. Pour cela, cette analyse historique fait usage les concepts de circulation et d'appropriation de Roger Chartier et utilise comme sources historiques notamment les rapports officiels et les rapports des enseignants.

Mots-clés: classes secondaires expérimentales, classes nouvelles, pédagogie personnalisée et communautaire. 
$\mathrm{D}$ e 3 a 22 de janeiro de 1955, em Santiago do Chile, realizou-se o Seminário Interamericano de Educação Secundária, promovido pela Organização dos Estados Americanos (OEA) e pelo Governo do Chile. Nesse congresso o Brasil foi representado pelo professor Jayme Abreu, que coordenava, no Instituto Nacional de Estudos Pedagógicos (Inep), a Campanha de Levantamentos e Inquéritos no Ensino Médio e Elementar (Cileme). O texto preparado por Jayme Abreu para esse congresso, bem como as suas impressões do mesmo foram agrupados no livro "A Educação Secundária no Brasil". (ABREU, 1955). Ao analisar o ensino secundário em escala americana, Abreu (1955, p. 154) constata: "Quanto à matrícula nas escolas secundárias o quadro publicado pelo Prof. Cebollero, relativo a 11 países americanos, mostra que o Brasil era o único em que a matrícula na escola pública era inferior à da escola particular". Em boa medida, essa situação configurou-se devido à aliança entre a alta hierarquia católica e o Governo Federal após a chamada Revolução de 1930, de sorte que somente a rede católica dirigia mais da metade dos colégios de ensino secundário. A Lei Orgânica do Ensino Secundário (1942), arquitetada por Gustavo Capanema na ditadura getulista, contemplava a pedagogia católica, prescrevendo o ensino tradicional, o elitismo, o currículo literário, o caráter excessivamente nacionalista e segregador de gênero, que previa a divisão de colégios e de turmas para adolescentes homens e mulheres.

A partir de 1945, com o fim da Segunda Guerra Mundial e a criação da Unesco, uma instituição educacional global, e o início da redemocratização da sociedade brasileira, passaram a ser implementados projetos e experiências escolares inéditas. No campo do ensino secundário, muito lentamente começaram a ser feitos ensaios renovadores, especialmente a partir de modelos pedagógicos norte-americanos e franceses. A partir de um convênio entre a Fundação Getúlio Vargas (FGV) e a Prefeitura de Nova Friburgo, em 11 de março de 1951 foi inaugurado o Colégio Nova Friburgo, que adotou o "Método de Unidades Didáticas", um projeto escolar fundamentado especialmente na noção de unidade do Plano Morrison - formulado pelo educador norte-americano Henri Morrison. A articulação dessa proposta pedagógica foi feita pela professora Irene Mello Carvalho, que visitara instituições de ensino secundário nos EUA e em países europeus e ressignificou para o Colégio Nova Friburgo o Plano Morrison, cujo texto foi publicado em forma de livro. (CARVALHO, 1956). Não sem razão, Irene Mello Carvalho apresentou o trabalho intitulado "O ensino por unidades didáticas" no Seminário Interamericano de Educação Secundária, que relata a experiência de aplicação didática de Morrison no Colégio Nova Friburgo. (ABREU, 1955). Assim, o educandário da FGV tornou-se referência na renovação do ensino secundário, sendo visitado por inúmeros educadores brasileiros.

Embora ainda não de forma prioritária, o ensino secundário brasileiro passou a integrar a pauta da educação nacional no início da década de 1950 tanto no Instituto Nacional de Estudos Pedagógicos (Inep) quanto na Diretoria do Ensino Secundário (DES) - órgãos do Ministério da Educação e Cultura. Sob a direção de Anísio Teixeira desde 1952, o Inep implementou várias campanhas para superar a fragilidade do sistema nacional de ensino, entre as quais a Cileme, coordenada por Jayme Abreu, que resultou na publicação de diversos trabalhos. (BERETA; DALLABRIDA; CLARINO, 2013). Sob a gestão de Armando Hildebrand, a DES criou uma campanha destinada a modernizar o ensino secundário, que se concretizou com o estabelecimento da Campanha Nacional de Difusão e Aperfeiçoamento do Ensino Secundário (Cades) por meio do Decreto no 34.638, de 17 de 
novembro de 1953. O objetivo principal da Cades era promover cursos para os professores leigos do ensino secundário, ministrados por docentes de grandes centros e realizados durante o período de férias, com o intuito de prepará-los para o exame de suficiência, que conferia o grau de licenciado. A relevância desses cursos deve-se ao fato de que, na década de 1950, havia mais de $80 \%$ de professores leigos que ensinavam em estabelecimentos de ensino secundário, emergência que justificava a criação de uma campanha. Em 1956, ao assumir a direção da DES, Gildásio Amado envidou esforços para criar um periódico de divulgação das experiências da Cades, materializado em junho de 1957 com a publicação da revista "Escola Secundária", que tinha uma perspectiva editorial didático-pedagógica e se manteve ativa e criativa por cinco anos. (ROSA, 2014).

A partir de 1952, no sistema público de ensino de São Paulo, começou a se implantar uma experiência pioneira, realizada pelo professor Luiz Contier no Instituto Alberto Conte e inspirada nas classes nouvelles francesas. Nos dois anos anteriores, Contier realizou estágio no Centre International d’Études Pedagogiques (Ciep), localizado em Sèvres, que desde 1945 vinha produzindo e aperfeiçoando uma proposta renovadora para o ensino secundário na França. (VIEIRA, 2015). O ensaio de Contier foi bem recebido pelo Ministério da Educação e Cultura, que permitiu a implantação das classes secundárias experimentais a partir de 1959. Assim, no início daquele ano letivo, essas classes começaram a ser implantadas em alguns estabelecimentos de ensino secundário. Além dos colégios públicos, alguns educandários católicos também colocaram em marcha essas classes experimentais, mas fundamentadas na Pédagogie Personnalisée, concebida e praticada pelo padre jesuíta francês Pierre Faure. (DALLABRIDA, 2017). Na avaliação das classes secundárias experimentais entre 1959 e 1962, Cunha e Abreu (1963) constatam que essa experiência pedagógica renovadora se realizou, nesse período, em 46 colégios, localizados em oito estados, sendo que a maioria pertencia aos estados de São Paulo e do Rio de Janeiro. Desta forma, o presente trabalho se propõe a compreender a circulação e a apropriação destes dois modelos pedagógicos franceses que foram as referências para a construção das classes secundárias experimentais.

Para ler essa questão, adota-se a perspectiva do historiador Roger Chartier (1992), que considera que os bens culturais são produzidos, disseminados e usados de forma diferente, de modo que a recepção é realizada com criatividade, por meio de resistências, ressignificações e arranjos. No campo escolar, a partir de reflexões de Carvalho (2003) e Rockwell (2005), considera-se que os modelos pedagógicos são produzidos em tempos e espaços específicos, circulam por meio de diferentes mediadores e suportes e são apropriados em diferentes instâncias dos sistemas educativos e, por fim, pelos professores em sala de aula. As fontes utilizadas nesta investigação histórica são livros, revistas, dissertações de mestrado e relatórios técnicos. Neste trabalho o foco de análise é, portanto, colocado sobre dois modelos pedagógicos produzidos na França no imediato pós-guerra, disseminados por meio de estagiários brasileiros em instituições educativas francesas e de educadores que fizeram visitas pedagógicas ao Brasil, bem como por meio de textos, como artigos em periódicos e livros, que foram apropriados por redes escolares e colégios.

\section{Classes nouvelles e a renovação do sistema público de ensino}

A criação das classes nouvelles na França é parte integrante do engajamento político e pedagógico de Gustave Monot, particularmente na conjuntura do imediato pós- 
Segunda Guerra Mundial. Licenciado em Letras, Monod foi convidado, em 1911, a lecionar Filosofia na École des Roches, instituição educacional privada e laica, fundada por Edmond Demolins e inspirada nas experiências escolanovistas de Abbotssholme e Dedalles School. Depois de participar da Primeira Guerra Mundial, ele voltou a lecionar Filosofia e a ministrar conferências em prol do pacifismo e da educação renovadora. Na Segunda Guerra envolveu-se na resistência e, no início de 1945, foi nomeado, pelo ministro da Educação do Governo Provisório, Diretor do Ensino Secundário - cargo estratégico no sistema de ensino francês. Nesse mesmo ano liderou a criação do Centre International d'Études Pedagogiques (Ciep), localizado em Sèvres, em parceria com o Ministério de Relações Exteriores e a Unesco, com o objetivo de criar intercâmbios entre países sobre a renovação pedagógica, e anunciou a instalação das classes nouvelles para o início do ano letivo 19456 em 140 colégios. Esse projeto, que contou com o auxílio de Paul Langevin, previa a implantação das classes nouvelles inicialmente na sixième classe do ciclo colegial2; no segundo ano na cinquième classe e assim sucessivamente até o último ano do ciclo colegial - a troisième classe. (LECOCQ; LEDERLÉ, 2008; ARAÚJO; DALLABRIDA, 2017).

Assim, segundo o Ministério da Educação Nacional da França, as classes nouvelles pretendiam oferecer um modelo pedagógico alternativo e inovador para o ensino secundário francês, que deveria apresentar, entre outros, os seguintes traços: turma com uma média de 25 alunos, redução do número de professores nas primeiras classes do ensino secundário, realização do conselho de classe semanal ou quinzenal, integração das disciplinas-saber e das tarefas escolares, uso de métodos ativos e cooperativos, estudo do meio natural e humano, aproximação do trabalho manual e trabalho intelectual, estímulo ao autogoverno e à individualização do ensino, estreitamento da relação entre pais e professores e ensino facultativo da língua latina. (CANGUILHEM et al., 1981). O estudo do meio havia sido uma prática educativa corrente nas experiências no ensino primário de corte escolanovista e passava a ser visto no ensino secundário como um princípio inovador fulcral nas classes nouvelles definido, pelo Ministério da Educação Nacional, da seguinte forma: "introdução do estudo do meio natural e humano [sic] para permitir que os professores liguem seu ensino à vida e, dessa forma, fazer com que os estudantes se conscientizem do mundo em que vivem, com as interações que unem os seus diferentes elementos e com a atividade que eles deverão exercer nele"3. (CANGILHEM et al, 1981, p. 145). As classes nouvelles, portanto, procuravam quebrar o tradicionalismo pedagógico focado na aula expositiva do professor.

Desde a sua fundação, o Ciep passou a ser uma referência importante para boa parte dos educadores brasileiros que buscavam renovar o ensino secundário. Assim, Marques (1985) afirma que em 1949 o Consulado Francês no Brasil passou a convidar professores para estagiar em Sèvres, sendo que um dos primeiros brasileiros a ir ao Ciep foi Luiz Contier, professor de Francês e então diretor do Instituto de Educação Alberto Conte

\footnotetext{
${ }^{2}$ No sistema de ensino francês, o ensino secundário era e ainda é formado por dois ciclos: o collège, formado por quatro classes/anos letivos (sixième, cinquième, quatrième e troisième) e o lycée, constituído por três classes/anos letivos (seconde, première e terminal). No Brasil, entre a Reforma Francisco Campos (1942) e a Lei 5.692, de 1971, o ensino secundário tinha estrutura similar do mesmo nível de ensino francês, ou seja, era formado pelos ciclos ginasial (com 4 classes/anos letivos) e colegial (com 3 classes/anos letivos), mas as classes de ambos os ciclos eram crescentes.

${ }^{3}$ Introduction de l'étude du milieu naturel et humain pour permettre aux professeurs de relier leur enseignement à la vie et de faire ainsi prendre conscience aux élèves du monde dans lequel ils vivent, des interréactions qui en unissent les divers éléments et de l'activité qu'ils devront eux-mêmes y exercer.
} 
de Santo Amaro, localizado na cidade de São Paulo. Contier realizou estágio no Ciep entre o início de 1950 e meados de 1951 e, ao retornar ao Brasil, deu início a uma experiência pedagógica renovadora no Instituto Alberto Conte. Esse ensaio educativo foi pautado por estratégias didáticas do ativismo, como trabalhos de pesquisa, estudo do meio e atividades em equipes, que foram apropriadas das classes nouvelles. (VIEIRA, 2015). Segundo Marques (1985, p. 25-26), a experiência pioneira do professor Luiz Contier adaptou o modelo pedagógico das classes nouvelles, mas ficou restrita ao método de ensino. Diz ela:

Após quase 2 anos de estudos (1950-1951), o prof. Contier, empolgado, iniciou em sua escola uma adaptação das "classes nouvelles" que denominou classes experimentais, por entendê-las como um processo educacional que poderia ser feito paralelamente, como na também se caracterizavam por desenvolver uma programação menos ambiciosa do que a das classes convencionais e por trazer os pais à escola. Mas o grande obstáculo que o prof. Contier encontrou foi o fato de ser apenas um diretor de uma escola estadual submetido a uma lei que não comportava experiências isoladas, permitindo apenas renovações metodológicas. Assim, o trabalho no "Alberto Conte" restringiu-se à introdução metodológica ativa no currículo convencional, direcionando suas críticas aos métodos obsoletos de ensino vigentes nas escolas brasileiras. (MARQUES, 1985, p. 25-26).

A iniciativa vanguardista no Instituto Alberto Conte teve ressonância na Inspetoria Secional de Ensino Secundário de São Paulo, de sorte que Luiz Contier apresentou as suas ideias inovadoras para o curso ginasial do ensino secundário na $1^{\underline{a}}$ Jornada de Estudos de Diretores de Estabelecimentos de Ensino Secundário, realizada em 1957. (CUNHA; ABREU, 1963). Gildásio Amado envidou esforços no sentido de regulamentar essas experiências no ensino secundário e, para tanto, formulou uma exposição de motivos ao Ministro da Educação e Cultura, que resultaria na publicação das "Instruções sobre a natureza e a organização das classes experimentais". (MINISTÉRIO DA EDUCAÇÃO E CULTURA, 1958), legislação que autorizava a instalação de classes experimentais nos cursos ginasial e colegial - ou seja, nos dois ciclos do ensino secundário - a partir do ano letivo de 1959. O seu item 3 estabelece "características das classes experimentais" determinando que, prioritariamente, elas deveriam ser implantadas no primeiro ciclo do ensino secundário, ou seja, no curso ginasial; em um número reduzido de classes, iniciando na primeira e, mediante avaliação, poderia ser expandida para as outras classes do ginásio. (DALLABRIDA, 2014). Essa legislação estabelecia estritos mecanismos de controle do Ministério da Educação e Cultura por meio da necessidade da prévia autorização e da "assistência especial" da Diretoria do Ensino Secundário e o credenciamento dos professores, bem como o "prévio consentimento dos pais ou responsáveis dos alunos matriculados". (BRASIL, 1958, p. 80). E determinavam as seguintes "normais gerais" para as classes secundárias experimentais:

a) na organização dos currículos, ter-se-á em vista não a especialização nesta ou naquela direção de estudos, mas na preparação geral com um sólido conteúdo de formação humana e maiores oportunidades de atendimento das aptidões individuais:

b) maior articulação do ensino das várias disciplinas e maior coordenação das atividades escolares;

c) número máximo de trinta alunos em cada classe, para que o ensino se possa adaptar melhor a cada aluno;

d) o número de professores nas classes iniciais do ginásio poderá ser reduzido para evitar os inconvenientes da transição brusca do regime primário para o secundário. 
Os professores terão, assim, convívio mais demorado com os alunos, podendo melhor examinar-Ihes as tendências e exercerem uma orientação eficiente;

e) reuniões periódicas dos professores de cada classe para a apreciação da classe nos seus aspectos psicológicos e sua melhor e mais homogênea orientação pedagógica;

f) possibilidade de opções que correspondem às aptidões dos alunos;

g) acentuação da função educativa da escola de maior permanência diária na escola e de participação nas atividades extracurriculares;

h) atividade dirigida, planejada de modo que o aluno dela possa participar ativamente, para adquirir seu método próprio de trabalho e hábitos de vida consciente e dinâmica;

i) articulação mais estreita entre professores e pais, tão necessária para a harmonia que deve existir entre a obra educadora da escola e da família. (BRASIL, 1958, p. 80-81).

Essas prescrições das classes secundárias experimentais indicam apropriação das classes nouvelles realizadas particularmente por Luiz Contier. Assim, houve um uso brasileiro do modelo pedagógico francês em relação à redução do número de alunos por sala, pois, enquanto nas turmas francesas o limite era de 25 alunos, nas classes secundárias experimentais o número máximo era de 30 estudantes. De outra parte, constata-se a presença de métodos ativos, da importância da orientação pedagógica no respeito às aptidões dos alunos, integração curricular, a imprescindível exigência da reunião periódica de professores, a tendência ao regime de tempo integral, especialmente pelo oferecimento de atividades extraclasse e o envolvimento dos pais dos alunos no trabalho escolar. O modelo prescrito para as classes secundárias experimentais, portanto, distanciava-se do padrão vigente do ensino secundário da Reforma Capanema - marcado pelo método tradicional e pela rigidez curricular.

No início do ano letivo de 1959, alguns colégios da rede pública de ensino do estado de São Paulo implantaram as classes secundárias experimentais, com destaque para o Instituto de Educação Narciso Pieroni da cidade de Socorro. Essa experiência educacional de referência, que ficou conhecida como as classes experimentais de Socorro, foi liderada por Lygia Forquim Sim, diretora do colégio e ex-estagiária no Ciep de Sèvres; Olga Bechara, professora de matemática e auxiliar da orientação educacional; e Maria Nilde Mascelani, orientadora educacional e mentora da proposta pedagógica renovadora. Segundo Vieira (2015), as classes secundárias experimentais de Socorro apresentaram os seguintes traços pedagógicos: trabalho dirigido, estudo do meio, priorização de métodos ativos, aproximação do estudante com o seu meio natural e humano, abolição do livro didático, substituído por textos docentes ou obras de referência e conselho de classe. Essas estratégias de ensino foram, em boa medida, apropriadas do modelo das classes nouvelles com ressignificação para o estudo do meio, que na escola de Socorro passou a ter um caráter mais sociológico através de práticas críticas de transformação social e de compromisso político com a comunidade local/regional. Assim, Vieira (2015, p. 74) esclarece:

A atividade do estudo do meio tinha como preocupação, no retorno às classes, possibilitar ao aluno adquirir noções de responsabilidade social em relação ao que fora observado. [...] Nesta direção, os estudos ocorriam em três etapas: a primeira de observação, onde os educandos levantavam os dados, seguida da etapa da associação, onde os alunos associavam-se espacial e temporalmente em relação aos tópicos estudados e, por fim, a fase de expressão, onde expunham o que haviam aprendido. 
Outro ensaio pedagógico que merece ser colocado em relevo foi realizado no Instituto de Educação de Jundiaí, localizado no interior do estado de São Paulo. Por um lado, por construir uma fundamentação pedagógica híbrida, que mesclava o modelo das classes nouvelles com a Pedagogia Personalizada e Comunitária de Pierre Faure. De outra parte, pelo fato de implantar, a partir de 1960, as classes secundárias experimentais tanto no curso ginasial como no ciclo colegial; e, quatro anos depois, teve autorização para funcionar totalmente em ritmo experimental - inclusive no curso normal. Desta forma, houve efetiva flexibilização curricular no ciclo colegial pela supressão da disciplina canto orfeônico, a possibilidade de escolha da língua estrangeira moderna (inglês ou francês) e a introdução da disciplina de Extensão Cultural. No curso científico foram criados dois ramos: o biológico, com foco nas ciências naturais, e o técnico, com ênfase nas ciências exatas. Entre as inovações didático-pedagógicas do Instituto de Educação de Jundiaí, destacaram-se o ensino em tempo integral e a diversificação do estudo do meio especialmente aglutinando áreas afins como matemática/física/química, história natural/geografia, geografia/ciências e português/história/línguas. (VIEIRA, 2017). Trata-se, portanto, de uma experiência educacional renovadora, mas politicamente moderada porque se estendeu até meados dos anos 1970, convivendo com a ditadura militar.

A circulação das classes nouvelles no Brasil deu-se, sobremaneira, pela realização de estágios de educadores brasileiros em Sèvres, mas também pela visita técnica de Edmée Hatinguais - diretora do Ciep - ao Brasil em 1954 e 1956 a convite do Governo Federal. (VIEIRA, 2015). Essa circulação de mão dupla viabilizou a circulação e a apropriação das classes nouvelles na rede pública de ensino do estado de São Paulo, desde o início da década de 1950, mas de forma controlada e pontual, isto é, em alguns institutos de educação, que contavam com o curso normal e, por isso, com profissionais da área de didática. $\mathrm{Na}$ experiência das classes secundárias experimentais de Socorro, o trabalho pedagógico de Maria Nilde Mascelani ganhou destaque, de sorte que ela foi convidada pelo secretário da educação do estado de São Paulo para coordenar a implantação dos ginásios vocacionais, projeto educacional inovador que desdobrou e ressignificou as classes experimentais. (CHIOZZINI, 2014). As classes secundárias experimentais, inspiradas nas classes nouvelles, converteram-se, portanto, na principal experiência de renovação do ensino secundário de caráter público, na década de 1950, no estado de São Paulo e no Brasil.

\section{A Pedagogia Personalizada e o aggiornamento da rede escolar católica}

Aproveitando a possibilidade estabelecida pela legislação vigente, a partir de 1959 alguns colégios católicos no Brasil iniciaram ensaios de transformação da cultura escolar do ensino secundário, fundamentados na Pedagogia Personalizada e Comunitária de Pierre Faure. Essa proposta educativa fora desenvolvida pelo padre jesuíta francês Pierre Faure a partir do uso de diversas matrizes pedagógicas e de um intenso trabalho educativo em constante ritmo de avaliação e de reformulação. Para compreendê-la, é importante constatar que o padre Faure iniciou a sua intervenção no campo escolar em 1937, quando criou, em Vanves, o Centre d'Études Pédagogiques e passou a colaborar em várias revistas pedagógicas. Três anos depois, em parceria com Hélène Lubienska de Lenval, ele começou a ministrar cursos de verão para capacitação docente e, posteriormente, estabeleceu, em Paris, um centro de estudos pedagógicos, três escolas normais e um 
colégio de aplicação. Em 1945, criou a revista Pédagogie e dirigiu-a até 1972, a qual se converteu no principal meio de divulgação da sua experiência educativa. (AUDIC, 1998). Contudo, a divulgação da Pedagogia Personalizada e Comunitária deu-se também com a visita do padre Faure a diversos países, quando ministrava cursos de formação docente e convidava professores para se aperfeiçoar no Centre d'Études Pédagogiques de Paris, que ele coordenava.

Segundo Klein (1998, p. 26), "Faure encontra a base pedagógica para a sua proposta nos autores clássicos, na Ratio Studiorum, na Escola Nova, no Plano Dalton, em Freinet e nas reformas educacionais francesas do pós-guerra". Entre os autores canônicos no Ocidente, destaca Platão e Michel de Montaigne, e entre os considerados precursores da Escola Nova coloca em relevo os enunciados pioneiros de Jean Jacques Rousseau e o trabalho educativo de Johann Heinrich Pestalozzi. O jesuíta francês expressou afinidades com o movimento da Escola Nova pelo fato de colocar o aluno no centro do processo de aprendizagem de forma ativa, mas criticou aquelas experiências educativas que poupam o estudante do trabalho pessoal e regular, têm descaso com os conteúdos e relaxam na formação de valores. Ele fez uso seletivo do Plano Dalton, criado nos EUA por Helen Parkhurst, como "o aproveitamento dos programas oficiais; a modificação do horário escolar; a organização das classes por disciplina e não por idade dos alunos; a programação, com a distribuição progressiva das noções; o plano de trabalho", mas criticava "a atomização da aprendizagem". (KLEIN, 1998, p. 27). Apreciou a criatividade e o empreendedorismo escolar de Célestin Freinet, mas censurou a sua ideologia marxista que não considerava a dimensão espiritual na formação integral, bem como o descaso com os autores clássicos. Em relação às reformas escolares colocadas em marcha na França a partir de 1945, apropriou-se, especialmente, do Plano Langevin-Wallon. (GUTIERREZ; $\mathrm{KAHN}, 2016$ ) e da experiência das classes nouvelles.

Em realidade, o padre Pierre Faure fez um uso seletivo do movimento escolanovista à luz do crivo católico. Não por acaso aproximou-se de Maria Montessori, que, além de dar ênfase à criação do ambiente e material educativos, provocando a autonomia da criança, contemplava traços religiosos no seu método pedagógico. Mais do que isso: conheceu o método montessoriano por meio das lentes ainda mais católicas de Hélène Lubienska de Lenval, com quem dividiu trabalhos educativos, especialmente no tocante à formação docente. (AVELAR, 1978). À luz do documento pontifício Divini Illius Magistri, publicado em 1929, que determinava diretrizes para a educação católica, Faure rechaçou, em meados do século XX, a coeducação, uma das bandeiras do movimento escolanovista em nível mundial. Como membro da Companhia de Jesus, apoiou-se tanto nos Exercícios Espirituais de Inácio de Loyola, relativamente à interiorização e à ação, como na Ratio Studiorum, que prescrevia um trabalho educativo pessoal dos alunos após a preleção do professor. (KLEIN, 1998). Desta forma, a proposta pedagógica do padre Faure constituiu-se em um hibridismo de matrizes escolanovistas que defendiam o ativismo do estudante filtradas pela perspectiva católica e, especificamente, jesuítica.

Embora às vezes haja referência ao "método de Pierre Faure". (AVELAR, 1978, p. 84), a educadora Maria Nieves Pereira prefere denominá-lo "Projeto Pedagógico de Pierre Faure" (PEREIRA DE GOMES, 1997, p. 16) porque se trata de uma proposta aberta e em constante experimentação. Opondo-se ao ensino tradicional, massivo e padronizado, Faure enuncia que o primeiro princípio da educação que defende é a "personalização", por isso a 
sua proposta ficou conhecida como "educação personalizada" (KLEIN, 1998, p. 40). Os outros princípios são a autonomia, o ativismo, a criatividade, a sociabilidade e transcendência - dimensão espiritual do humanismo fauriano. O último livro do pedagogo jesuíta é sintomaticamente intitulado "Ensino personalizado e comunitário", sublinhando não haver oposição entre a personalização e a sociabilidade porque o desafio educativo não é justapor os alunos, mas colocá-los em rede de cooperação. Faure (1975 apud KLEIN, 1998, p. 48-49) esclarece:

A formação social não se opõe à formação pessoal. Se há verdadeira personalização, ela conduz necessariamente à formação social porque o homem, a criança traz em si uma natureza que os conduz a se interiorizar e se exteriorizar, se aprofundar pessoalmente e se comunicar, se aprofundar pessoalmente e se comunicar socialmente [...]. Não se trata da formação pessoal de um lado e a formação social de outro, pois isso não corresponde à realidade, mas é um problema que só se coloca no papel. A realidade é que o pessoal conduz ao social e o social ao pessoal.

As dimensões personalizadora e comunitária do projeto pedagógico de Pierre Faure estão materializadas nos seus instrumentos de trabalho e nos seus momentos didáticos. Os primeiros são formados inicialmente pela programação - seleção de conteúdos e técnicas realizadas pelo professor para estimular o trabalho pessoal do estudante, que deve se adequar às prescrições de regiões e de países, mas deve ir além delas; plano de trabalho definido pelo estudante; uso de guias ou fichas para o trabalho pessoal do estudante, o que não dispensa a aula coletiva do professor; e o material didático, formado por biblioteca de sala de aula ou uma comum a várias salas com livros e documentos, material sensório-motor, material audiovisual, bem como material de autocontrole do aluno. Os momentos didáticos (trabalho independente, trabalho grupal, partilha, síntese e registro pessoal, exposição oral e escrita e avaliação contínua) não têm uma ordem fixa, podendo ser flexibilizados de acordo com as necessidades dos estudantes. Nessa dinâmica não há exames padronizados, porque o tempo é flexível segundo o ritmo e as capacidades de cada estudante, e nem repetência de série, de sorte que para aqueles alunos que não conseguem cumprir a programação é oferecida a classe de aperfeiçoamento. Desse modo, o professor deveria converter-se em organizador de roteiros de aprendizagens, instigador, animador, provocador e conselheiro, conforme prescrevia o movimento escolanovista. Enfim, o ensino personalizado e comunitário procurava proporcionar uma educação integral, que incluía a dimensão social - distanciando Faure de Montessori e Lubienska - e a dimensão espiritual de corte católico-jesuítico. (KLEIN, 1998).

Com o intuito de disseminar a sua proposta pedagógica, o padre Faure esteve no Brasil, a convite da Associação de Educação Católica (AEC), para animar as "Semanas Pedagógicas", sendo que a primeira se realizou, em 1955, no Colégio Sacre Coeur do Rio de Janeiro, e a segunda, em meados do ano seguinte, foi sediada no Colégio Sion de São Paulo. Esses encontros com diretores e professores resultaram na implantação no Brasil do método Montessori-Lubienska na educação infantil e no curso primário, particularmente na rede escolar católica. Em janeiro de 1959, o educador jesuíta ministrou um curso de formação de professores do ensino secundário de colégios que pretendiam implantar as classes secundárias experimentais naquele ano letivo. Esse curso também ocorreu na cidade de São Paulo e envolveu gestores e docentes dos colégios Santa Cruz, Sion e o das Cônegas de Santo Agostinho, que se tornaram pioneiros na implantação das classes 
secundárias experimentais no campo educacional católico. (AVELAR, 1978; SAVIANI, 2008). Trata-se de três educandários dirigidos por congregações francófonas, sendo duas femininas e de ascendência francesa e uma masculina de origem canadense - a Congregação dos Padres de Santa Cruz. Em boa medida essa iniciativa deve-se ao fato de um pequeno grupo de padres e freiras dessas congregações católicas terem realizado um estágio em Paris, em 1958, com o padre Faure.

O Colégio Santa Cruz, localizado no bairro paulistano de Alto de Pinheiros e dirigido por sacerdotes canadenses da congregação dos Padres da Santa Cruz, implantou uma classe experimental do curso ginasial a partir de 1959. Para tanto, no ano anterior, o diretor do colégio enviou o padre Yvon La France para Paris com o objetivo de realizar um estágio no Centre d'Études Pédagogiques, sob a orientação do padre Faure. (LA FRANCE, 1959). De outra parte, nas férias de 1959, o padre Faure preparou parte do corpo docente e dirigente do Colégio Santa Cruz para implantarem, a partir de março, um ensaio pedagógico renovador calcado na pedagogia fauriana, que seria liderada pelo padre La France e contaria com um grupo motivado de professores religiosos e leigos. A constituição da turma do curso ginasial experimental deu-se inicialmente através do exame de admissão, do consentimento dos pais e, devido à grande procura e para evitar turma homogênea, por sorteio. (LA FRANCE, 1963). O estabelecimento do ensino por meio da pesquisa orientada pelas fichas de trabalho - técnica apropriada do método de Pierre Faure - era a pedra de toque da inovação escolar colocada em marcha no colégio dos padres de Alto de Pinheiros. De forma diversa das classes tradicionais, marcadas pela aula expositiva, a classe experimental iniciava pela orientação do professor sobre o tema da pesquisa, a ser realizada de modo individual pelos alunos, mas posteriormente tinha momentos de socialização de conhecimentos em equipes e com todo o grupo da classe. (SCHREIBER, 2016).

A pesquisa realizada por meio de fichas de trabalho demandava uma nova disposição na sala de aula, de maneira que as carteiras eram móveis, viabilizando o trabalho em equipes e mesmo experiências que utilizavam várias carteiras. A classe experimental do curso ginasial também tinha três salas ambientes: a de artes plásticas e trabalhos manuais; a de ciências naturais, que era separada das áreas de biologia, química e física; e a de projeção e música, com equipamentos que projetavam imagens para as disciplinas de história e geografia e para o cineclube, bem como de uma vitrola e um piano. De outra parte, essa classe experimental tinha uma nova organização temporal, estruturada por quinzenas de trabalho escolar, que eram formadas por 12 a 18 dias, de modo que a quinzena terminava sempre aos sábados. Como o Colégio Santa Cruz funcionava em regime de semi-internato - período integral -, na parte da manhã eram trabalhadas as disciplinas que demandavam mais esforço mental, como português e matemática, bem como a pesquisa individual dos alunos. Após o almoço, feito no colégio, eram realizadas atividades mais práticas como educação física, trabalhos manuais e práticas de laboratório; a partir do meio da tarde eram ministradas disciplinas intelectuais - história, geografia e línguas. (SCHREIBER, 2016). Essa disposição escolar destoava das classes regulares do Colégio Santa Cruz bem como das classes da grande maioria dos educandários da época.

Além de prestar assessoria e de ministrar cursos de formação de professores aos colégios católicos, Pierre Faure fez circular a sua perspectiva pedagógica através da publicação de diversos artigos na Servir, revista da Associação de Educação Católica 
(AEC), criada em 1948 com o intuito de fortalecer a rede de colégios católicos no momento da redemocratização da sociedade brasileira, quando passou a haver mais concorrência no campo educacional. Por ocasião do falecimento de Maria Montessori, Faure (1953) publicou um pequeno mas emblemático texto rememorando a contribuição da educadora italiana para a renovação pedagógica do século XX. Dois anos depois, o educador francês publicou os artigos Que penser des écoles nouvelles? (O que pensar das escolas novas?) (FAURE, 1954a) e Écoles nouvelles et pedagogie chrétienne (Escolas Novas e pedagogia cristã). (FAURE, 1954b). Nesses dois textos ele revisita a história do movimento da Escola Nova a partir do filtro católico-jesuítico e coteja os princípios pedagógicos das Escolas Novas e da tradição educacional católica, atualizada pela Encíclica Divini Illius Magistri. Os textos do padre Faure na revista Servir foram publicados na língua do seu país de origem, fato que indica o prestígio que o francês ainda tinha na sociedade brasileira nos anos 1950 .

A partir da iniciativa pioneira paulistana, as classes secundárias experimentais fundamentadas na Pedagogia Personalizada e Comunitária passaram a circular e a ser usadas em outros educandários católicos, especialmente por aqueles sediados na cidade de São Paulo e no Distrito Federal. O padre Faure veio ao Brasil animar dirigentes escolares e realizar formação de professores com regularidade nas décadas de 1960 e 1970, de maneira que, depois da França, o Brasil foi o país onde a sua pedagogia mais circulou e foi colocada em prática nas escolas. Essa vitalidade fez com que os ensaios das classes secundárias experimentais prosperassem mais nos colégios católicos, animados pela Pedagogia Personalizada e Comunitária, do que nas redes públicas de ensino.

\section{Considerações finais}

A renovação do ensino secundário aconteceu, de forma mais efetiva, nos anos 1950, por meio de implantação das classes experimentais a partir da apropriação de modelos pedagógicos norte-americanos e franceses. Entre os primeiros destacou-se o Plano Morrison, que deu fundamentação pedagógica para a inovação escolar colocada em prática no Colégio Nova Friburgo, inspirando, entre outras experiências similares, aquela desenvolvida no Colégio Estadual do Paraná. (CHAVES JÚNIOR, 2017). As classes nouvelles e a Pedagogia Personalizada e Comunitária converteram-se nos modelos pedagógicos franceses que estribaram a renovação do ensino secundário de maior alcance no Brasil, respectivamente nos colégios públicos e nos educandários católicos. O epicentro dessa onda renovadora de inspiração gaulesa deu-se no estado de São Paulo, de sorte que a apropriação das classes nouvelles ocorreu, de forma pioneira, pela iniciativa do professor Luiz Contier no Instituto Alberto Conte, mas, posteriormente, espraiou-se sobretudo na rede pública de ensino e teve como referência principal as chamadas classes experimentais de Socorro, dirigidas por Maria Nilde Mascelani. Em boa medida, essa experiência educacional foi muito utilizada pelos chamados ginásios vocacionais na década de 1960. De outra parte, a Pedagogia Personalizada e Comunitária teve o uso inédito, a partir de 1959, em alguns colégios católicos da cidade de São Paulo, mas logo disseminouse, de forma restrita e cuidadosa, pela rede católica de ensino.

Segundo a avaliação das classes secundárias experimentais no Brasil realizada por Cunha e Abreu (1963, p. 146), em 1962 havia "uma predominância maciça das escolas particulares, e nelas das confessionais, numa proporção aproximada de dois terços de particulares para um terço de públicas, sendo as classes em maioria para clientela feminina 
e de elite social". Essa divisão indica, seguramente, a tendência à elitização das experiências vinculadas ao movimento da Escola Nova, acusação feita sobretudo por educadores de corte marxista tanto no mundo euro-americano como no Brasil. E é importante constatar que, entre as escolas confessionais, a grande maioria era formada por educandários vinculados a congregações católicas de ascendência francesa, que passaram a ser animados e modernizados pela pedagogia renovadora do padre Faure. Se na década de 1930 a Igreja Católica posicionou-se, sobremaneira, contrária ao Manifesto dos Pioneiros da Educação Nova (1932), nos anos 1950 ela procurava apropriar-se das matrizes escolanovistas que contemplassem a dimensão espiritual da educação integral, como o Método Montessori-Lubienska, bem como ressignificar técnicas didáticopedagógicas de diferentes métodos ativos. Assim, a maior parte dos ensaios das classes secundárias experimentais foram realizados no curso ginasial de colégios de padres e de educandários de freiras, que ainda tinham clientelas divididas por gênero.

Enfim, é importante sublinhar que, na década de 1950, as classes nouvelles e a Pedagogia Personalizada e Comunitária tiveram circuitos e usos escolares bem específicos. As primeiras tiveram publicados os seus documentos normativos e o balanço dos primeiros quatros anos na Revista Brasileira de Estudos Pedagógicos, editada pelo Inep, que era dominado pelo grupo de renovadores da educação nacional e liderado por Anísio Teixeira. E foram apropriadas inicialmente por Luís Contier no estado de São Paulo, porém a partir de 1959 tiveram expansão em cursos ginasiais de institutos de educação, tendo como referência mais criativa as classes experimentais de Socorro. De outra parte, a Pedagogia Personalizada e Comunitária foi usada inicialmente em colégios católicos de ascendência francesa na cidade de São Paulo, mas disseminou-se em educandários da rede que pertencia à Igreja Católica, e os textos de Pierre Faure circularam na revista Servir. No entanto, não houve uma divisão rigidamente dicotômica da circulação e apropriação desses modelos pedagógicos no Brasil porque a Pedagogia Personalizada e Comunitária também foi usada no Instituto de Educação de Jundiaí.

\section{Referências}

ABREU, Jayme. A Educação Secundária no Brasil. Rio de Janeiro: Mec/lnep, 1955. (Publicações da Cileme, 9).

ARAÚJO, Elisabete; DALLABRIDA, Norberto. Gustave Monod e a renovação do ensino secundário francês. Acta Scientiarum - Education, Maringá, n. 39, p. 475-481, dez. 2017.

AUDIC, Anne-Marie. Pierre Faure s. j. 1904-1988: vers une pédagogie personnalisée et communautaire. Paris: Éditions Dom Bosco, 1988. (Collection Sciences de L’Éducation).

AVELAR, Gersolina Antônia de. Renovação Educacional Católica: Lubienska e sua influência no Brasil. São Paulo: Cortez \& Moraes, 1978.

BERETA, Cristiane; DALLABRIDA, Norberto; CLARINO, Juliana Maués da Silva. A perspectiva de Jayme Abreu sobre a reforma do Ensino Secundário no contexto do CBPE entre 1955 e 1964. In: COLÓQUIO ENSINO MÉDIO, HISTÓRIA E CIDADANIA, VIII, 2013. Anais... Florianópolis: Udesc, 2013. Disponível em: <http://www.revistas.udesc.br/ index.php/EnsinoMedio/article/view/3911/2724>. Acesso em: 31 mar. 2015.

CANGUILHEM, Georges et al. Gustave Monot - un pionnier en éducation: les classes nouvelles de la Libération. Paris: Comité Universitaire d’Information Pédagogique, 1981. 
CARVALHO, Irene Mello. O ensino por unidades didáticas: seu ensaio no Colégio Nova Friburgo. Rio de Janeiro: Ministério da Educação e Cultura, 1956. (Publicações da Cileme, 4)

CARVALHO, Marta Chagas de. A Escola e a República e outros ensaios. Bragança Paulista: Edusf, 2003.

CHARTIER, Roger. VI. Textos, impressões, leituras. In: HUNT, Lynn (Org.). A nova história cultural. São Paulo: Martins Fontes, 1992. p. 211-238.

CHAVES JÚNIOR, Sérgio Roberto. "Um embrião de laboratório de pedagogia": as classes integrais do Colégio Estadual do Paraná no contexto das inovações pedagógicas no ensino secundário (1960-1967). 2017. 250 f. Tese (Doutorado em Educação) Universidade Federal de Minas Gerais, Belo Horizonte, 2017.

CHIOZZINI, Daniel Ferraz. História e Memória da Inovação Educacional no Brasil: 0 caso dos Ginásios Vocacionais (1961-70). Curitiba: Editora Appris, 2014.

CUNHA, Nádia; ABREU, Jayme. Classes Secundárias Experimentais: balanço de uma experiência. Revista Brasileira de Estudos Pedagógicos, Rio de Janeiro, v. XL, n. 91, p. 90-151, 1963.

DALLABRIDA, Norberto. As classes secundárias experimentais: uma tradição escolar (quase) esquecida. Revista Brasileira de História da Educação, Maringá-PR, v. 17, n. 3 (46), p. 213-34, jul./set. 2017.

O MEC-INEP contra a Reforma Capanema: renovação do ensino secundário na década de 1950. Perspectiva, Florianópolis, v. 32, n. 2, p. 407-427, maio/ago. 2014.

FAURE, Pierre. Écoles nouvelles et pedagogie chrétienne. Servir - Órgão da AEC do Brasil, Rio de Janeiro, n. 2, p. 21-22, jun. 1954b. 1953.

. Maria Montessori. Servir - Órgão da AEC do Brasil, Rio de Janeiro, n. 2, p. 5, jun.

Que penser des écoles nouvelles? Servir - Órgão da AEC do Brasil, Rio de Janeiro, n. 1, p. 4-11, mar. 1954a.

GUTIERREZ, Laurent; KAHN, Pierre (Orgs.). Le plan Langevin-Wallon: histoire et actualité d'une reforme de l’enseignement. Nancy: Éditions Universitaires de Lorraine, 2016.

KLEIN, Luiz Fernando. Educação personalizada: desafios e perspectivas. São Paulo: Edições Loyola, 1998.

LA FRANCE, Yvon. As classes experimentais no Colégio Santa Cruz. Servir, Boletim da AEC do Brasil, n. 12, p. 24-30, 1959.

. Uma experiência psico-pedagógica no Colégio Santa Cruz (1959-1962). Revista de Psicologia Normal e Patológica, São Paulo, n. 3-4, p. 1-103, 1963.

LECOCQ, Tristan; LEDERLÉ, Annick. Gustave Monod: une certaine idée de l'école. Sèvres: Ciep, 2008.

MARQUES, Sandra M. L. Contribuição ao estudo dos ginásios vocacionais do

Estado de São Paulo: o Ginásio Vocacional "Chanceler Fernandes" de Rio Claro. 1985. 320 f. Dissertação (Mestrado em Educação) - PUC-SP, São Paulo, 1985.

MINISTÉRIO DA EDUCAÇÃO E CULTURA. Diretoria do Ensino Secundário. Instruções sobre a natureza e a organização das classes experimentais. Revista Brasileira de Estudos Pedagógicos, Rio de Janeiro, v. 30, n. 72, p. 79-83, dez. 1958. 
PEREIRA DE GÓMES, Maria Nieves. Educação personalizada: um projeto pedagógico em Pierre Faure. Bauru: Edusc, 1997.

PROST, Antoine. Histoire de l'enseignement et de l'éducacion: IV. Depuis 1930 L'École et la Famille dans une société e mutation. Paris: Perrin, 1981. (Tempus).

ROCKWELL, Elsie. 1. La apropiación, un proceso entre muchos que ocurren en ámbitos escolares. Anuário de la Sociedad Mexicana de Historia de la Educación, México, n. 1, p. 28-38, enero 2004/mayo 2005.

ROSA, Fabiana Teixeira da. Circulação de ideias sobre a renovação pedagógica do ensino secundário brasileiro em periódicos educacionais científicos (1956-1961). 2014. 140 f. Dissertação (Mestrado em Educação) - Centro de Ciências Humanas e da Educação, Universidade do Estado de Santa Catarina, Florianópolis, 2014.

SAVIANI, Demerval. História das ideias pedagógicas no Brasil. Campinas, SP: Autores Associados, 2008. (Coleção Memória da Educação).

SCHREIBER, Stefanie. Cultura escolar no curso ginasial experimental do Colégio Santa Cruz (1959-1962). 2016. 72 f. Trabalho de Conclusão de Curso (Graduação em História) - Centro de Ciências Humanas e da Educação, Universidade do Estado de Santa Catarina, 2016.

VIEIRA, Letícia. Das classes experimentais à escola experimental: o Instituto de Educação de Jundiaí. São Paulo: Universidade de São Paulo, 2017. Inédito.

. Um núcleo pioneiro na renovação da educação secundária brasileira: classes secundárias experimentais do Estado de São Paulo (1951-1964). 2015. 129 f. Dissertação (Mestrado em Educação) - Centro de Ciências Humanas e da Educação da Universidade do Estado de Santa Catarina, Florianópolis, 2015.

NORBERTO DALLABRIDA é Doutor em História pela Universidade de São Paulo (USP) e professor do Programa de Pós-Graduação em Educação da Universidade do Estado de Santa Catarina (Udesc). Pesquisador do CNPq. Com Rosa Fátima de Souza, organizador da coletânea "Entre o ginásio de elite e o colégio popular: estudos sobre o ensino secundário no Brasil (1931-1961)".

Endereço: Rua Henrique Bruggemann, 40 - ap. 304, Centro, 88015-650, Florianópolis/SC, Brasil.

E-mail: norbertodallabrida@gmail.com

Recebido em 26 de fevereiro de 2018.

Aceito em 25 de junho de 2018. 